in support of the 'Presapiens' thesis, as expounded by him, have had a mixed reception among students of human palæentology. Thus the veteran Prof. Sergio Sergi, in a paper devoted to the Swanscombe and Fontéchevade remains ${ }^{3}$, emphasizes the uncertainty of an adequate morphological diagnosis from them owing to their incompleteness. While acknowledging that they possess some traits in common with Homo sapiens such as the absence of a supra-orbital torus in Fontéchevade and certain metrical features in Swanscombe, he believes that their platycephaly, great biasterionic diameters, and posterior expansion of the base of the parietals are structurally archaic features the importance of which has been underestimated. In other words, it is not possible to recog. nize different pre-Neanderthal and 'Presapiens' groups much before the Wuirm. For Sir Wilfrid Le Gros Clark the morphological traits of Swanscombe and Fontéchevade as well as those of other European fossils, for example, Steinheim, Ehringsdorf, Krapina and Saccopastore, do not justify their specific separation from Homo sapiens ${ }^{4}$. This view, then, while acknowledging the sapient features of Swanscombe and Fontéchevade, does not differentiate them taxonomically from forms which Prof. Vallois would classify as pre-Neanderthals, and it regards classic Neanderthal man as comprising an aberrant evolutionary line which left the precursors of modern man when they had already attained a stage at which they were indistinguishable from Homo sapiens.

J. C. Trevor

${ }^{1}$ Biometrika, 18, 1 (1926).

${ }_{2}, J$. Roy. Anthrop. Inst., 68, 67 (1938).

${ }^{3}$ Riv. Antrop., 40,65 (1953).

" "The Fossil Evidence for Human Evolution" (Chicago, 1955)

\title{
PLANT ECOLOGY OF ANCIENT PERIODS
}

$\mathrm{T}$ HREE palæobotanists contributed papers to a symposium on palæoecology held at the Linnæan Society on March 19. They agreed on a wide definition of ecology, being ready to include almost anything that could be learnt from plant fossils, apart from their taxonomy and their morphology. After that, each speaker went his own way and confined himself to material he had studied in both the field and laboratory.

Dr. Kathleen Chesters spoke about the Tertiary floras of the coastal parts of Kent, Sussex, Hampshire, Dorset and Devon. She emphasized how difficult collecting has now become in this stretch of coast; and also dealt with the cliffs of Mull, where one can do little without explosives (Starkie Gardener, the pioneer, used dynamite). She dealt mainly with the nature and validity of evidence; apart from deductions from geology and from fossil animals, we have two main kinds of evidence from plants.

First, there is ecological form and ecological anatomy. The plant world of the Tertiary seems so like our own, and plants appear to have changed so little that we can reasonably use arguments based on the modern plant world. For example, we know that the proportion of trees with leaves (or leaflets) with entire margins increases from cool climates to the tropics. Then, also, leaves with drip tips are much commoner in rainy than in dry climates. Growth rings in wood indicate seasonal growth, and to-day, usually a winter resting season. All this evidence is available without a specific or generic determination, but where there is such determination it is possible and legitimate to inquire in what climatic zones most of the genera flourish to-day; or even in what country they are found. Where both lines of evidence coincide, as in general they do, one has impressive evidence. Dr. Chesters briefly made a case for likening the Eocene floras to those of Malaya, but the Mull flora (not yet securely dated) to the warm temperate floras of China and Japan.

Prof. T. M. Harris (Reading) said that the corresponding arguments were largely useless in the Jurassic because nothing like the Jurassic flora exists anywhere on earth. A quarter of the species belong to extinct families and the rest to relic families (like Gingko and Thyrsopteris and Matonia). Gymnosperm leaves are too different from those of angiosperms to allow reasonable comparison of their ecological form, and he suggested that the more tender ones were simply deciduous and the tough ones evergreen. $\mathrm{He}$ could not answer reasonable questions about past climates, but could only supply unexpected ecological crumbs, such as that forest fire was widespread and rather frequent in the Jurassic.

In the Yorkshire Deltaic flora the frequency of ferns might indicate a humid atmosphere, but the rarity of epiphytes rather suggests dryness. He showed that the Delta included three floras, swamps of Equisetum, often preserved intact; trees and herbs of the river banks represented by detached leaves but nowhere preserved as they grew, and, finally, tiny plant fragments. These last are the most varied, numerous and widespread and may represent floras of inland habitats washed down by occasional floods.

Dr. W. S. Lacey (Bangor) dealt with his recent experiences when collecting in the Karoo series of the Upper Zambezi in Southern Rhodesia. He drew more on geological evidence than the previous speakers. This great series of inland origin extends from the Upper Carboniferous to the Jurassic. It begins, as in South Africa, with Dwyka glacial deposits (tillites and varved clays), but farther north in Nyasaland there is no glacial deposit but only torrent-carried boulders.

The earliest floras are too little known to be useful, but the succeeding rich flora of Upper Wankie sandstone and the $40-\mathrm{ft}$. thick coal seam are taken to indicate good conditions for plant growth. The admixture of Glossopteris, Gangamopteris and of Northern (mostly European) Upper Carboniferous or Lower Permian species was also held to indicate warmth, since they are supposed to have lived in a very warm climate in Europe. Later stages, though still with a rich Glossopteris flora, have lost both the genus Gangamopteris and the Northern species. They are followed by Triassic floras with Dicroidium and the conifer-like Dadoxylon the growth rings of which seem significant. Still later there are freshwater concretionary limestones which may indicate evaporating lakes, and finally extensive fossil sand dunes indicating a hot, dry desert.

Dr. Lacey said he hesitated to regard Gangamopteris as an indicator of a glacial or even cold climate. He 
thought the whole sequence indicated a progressive warming and desiccation of the climate, though inter. rupted by seasonal torrential rains. At several stages no plants are known, but their presence is indicated by herbivorous reptiles, and the appearance of Crustacea characteristic of the European Carboniferous may indicate considerable warmth in the later stages.

In the discussion (which proved to have needed more time than was allotted) many observations were made. Dr. Chesters confirmed the existence of mangroves in the English Eocene and also stated that epiphytes had still not been found. There were apparently opposed statements about the rate of decay of plant remains in tropical muds which called for a series of experiments to find out the truth. One of the Upper Karoo plants (Lepidopteris stormber. gensis) was compared with a modern waterside aquatic herb, with which it agrees in that some small leaves, presumed to be lower ones, have more numerous stomata above than below. Its other leaves are normal. Others pointed out that lime. stones are forming to-day in East African lakes quite apart from evaporation of the water.

Dr. Hamshaw Thomas ended the discussion fittingly by suggesting that the early floras, like none on earth, grew in climates like none on earth to-day, but just how these climates differed he left us to ponder.

TOM M. HARRIS

\section{WEATHER MODIFICATION IN THE UNITED STATES}

$\mathrm{T}$ HE National Science Foundation has recently initiated a programme in which $1,130,000$ dollars will be distributed in thirteen grants for laboratory research, field experiments and conferences on meteorological methods directed toward modification of weather. The programme aims at an intensive study of the scientific basis of weather control, through the support of scientists working in cloud physics and allied fields.

Seven of the grants will make extensive use of experiments in the field to study the formation and characteristics of clouds, and possible changes in clouds induced by man.

Horace R. Byers and Roscoe R. Braham of the Department of Meteorology, University of Chicago, have received a grant of 114,300 dollars for a study of the physical effects of silver iodide seeding over the Great Plains. Cloud seeding in mountainous areas of the Pacific coast appears to result in measurable increases in precipitation. Over the flat terrain of the Great Plains, however, positive results have not been shown. This project will therefore release silver iodide nuclei from aircraft and investigate the resultant physical changes in the clouds themselves, rather than attempt to measure statistical departures in precipitation.

A. Richard Kassander, Louis J. Battan, and James E. McDonald of the Institute of Atmospheric Physics, University of Arizona, have received a grant of 161,800 dollars to study the physies of clouds and of cloud modification. In recent cloud-sceding experiments it was discovered that mean rainfall was approximately 30 per cent higher on seeded than on non-seeded days, and lightning flashes were about nine times more numerous on seeded days. These investigations will continue in an attempt to improve knowledge of the development of clouds, precipitation and electrification.

Robert D. Elliott of Aeromotric Research, Inc., Goleta, California, will conduct an investigation of precipitation processes and efficiency of Pacific coast storms with a grant of 90,500 dollars. Statistical data on west coast storms are already available from the Statistical Laboratory of the University of California at Berkeley, and elsewhere. An intensive effort will now be made to obtain physical data on west coast storms, including water content, nuclei number, potential gradient, and standard meteorological parameters. This will then be combined with the statistical data to develop, it is hoped, a complete model of a west coast storm.

Dwight B. Kline of the United States Weather Bureau, Department of Commerce, will direct an 18-month programme with a grant of 68,900 dollars, on synoptic observations and studies of freezing nuclei anomalies. It has been observed that about 30 days after known meteor showers on the Earth, a peak is reached in the number of freezing nuclei in clouds, in widely separated geographical locations. Other apparent coincidences between meteor showers and freezing nuclei have been noted. The U.S. Weather Bureau will conduct a systematic collection of results on freezing nuclei taken at widely scattered places at the same time. It is hoped that definitive information on the effects of meteoric dust on cloud nuclei can be obtained from this study.

The Atmospheric Research Group of Pasadena, California, will receive a 57,100 dollar grant to conduct field studies in cloud physics related to nucleation, hydrometeor development, electrification, and cloud dynamics. Field studies of small, 'simple' clouds will be conducted to investigate the effects of time, temperature, humidity, and drop-size on nucleation. Cloud seeding will be used as a research tool, most of the field measurements being carried on in the region of Flagstaff, Arizona.

The National Science Foundation has transferred 50,000 dollars to the Office of Naval Research in support of eloud electrification studies by A. D. Little, Inc., under the direction of Bernard Vonnegut. This work involves studies of the precipitation process and the processes at work in the electrification of thunderstorms.

Meteorology Research, Inc., will receive, subject to satisfactory completion of negotiations, a 40,000 dollar contract for two-year cloud-physics studies at Santa Barbara, under the direction of Paul MacCready, using radar to describe individual storms in great detail, to determine differences between storms, and formulate hypotheses on the relative seedability of various storms.

A laboratory project will be carried out in the Department of Meteorology of the University of Chicago, where Horace R. Byers has received a threeyear grant of 383,700 dollars for research in cloud physics, covering the factors believed to be important in precipitation mechanisms : particles and nuclei, ice nucleation processes, and the growth of ice crystals and water droplets. 